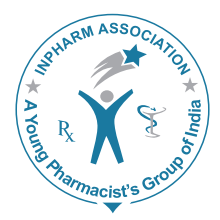

\title{
JVP
}

\section{Assessment of the impact of pharmaceutical advertisements on patient's drug consuming behavior: A questionnaire based survey}

\author{
Canna Ghia ${ }^{1 *}$, Rajesh Jha1, Gautam Rambhad ${ }^{2}$ \\ ${ }^{1}$ Department of Pharmacology, Jawaharlal Nehru Medical College, Wardha, Maharashtra, India, \\ ${ }^{2}$ Wyeth Limited (A subsidiary of Pfizer Inc.), Mumbai, Maharashtra, India
}

\begin{abstract}
Objective: The objective was to assess of the impact of pharmaceutical advertisements on patients drug consuming behavior. Methodology: This was 6 months cross-sectional survey using a validated open-ended scored questionnaire administered to 300 respondents. The locus of the study was a tertiary care rural hospital in India. The respondents were pre-briefed about the study. Voluntary participation and strict confidentiality were maintained. Responses to the questionnaire were evaluated and analyzed statistically. Results: Our results showed that pharmaceutical advertising has an important effect on drug consuming behavior of patients. It was seen that advertisements featuring antacids, health tonics and supplements, analgesic tablets and creams, antiflatulents and digestives, cold rubs and tablets as well as cough syrups had a high recall value (>50\%). It was seen that patients were keen on buying the drugs after an exposure to direct-to-consumer advertising (DTCA). Conclusions: DTCA does have an impact on consumer behavior. Increasing the health messages in advertisements, with less emphasis on the specific medication and more on the overall disease state is the moral obligation on the part of the pharmaceutical industry.
\end{abstract}

Key words: Direct to consumer advertising, pharmaceutical advertisements, consumer behavior

\section{INTRODUCTION}

Research in areas of pharmacy, therapeutics and biomedical technology has seen a revolution in the last three decades. ${ }^{1}$ It has brought out innovative molecules for the betterment of mankind. For ensuring a steady demand and supply of these products to physicians, pharmaceutical manufacturers have traditionally deployed a large number of sales forces. And

\begin{tabular}{|c|l|}
\hline \multicolumn{2}{|c|}{ Access this article online } \\
\hline \multirow{2}{*}{ Journal Sponsor } & \\
\hline & $\begin{array}{l}\text { Website: } \\
\text { www.jyoungpharm.org }\end{array}$ \\
\cline { 2 - 3 } www.phcog net & $\begin{array}{l}\text { DOI: } \\
10.5530 / j y p .2014 .2 .9\end{array}$ \\
\hline
\end{tabular}

with the advent of technology, pharmaceutical companies are also relying on different means to market their products which include "direct-to-consumer advertising" (DTCA). ${ }^{1}$

In today's world, advertising is a powerful force that plays a significant role in shaping the attitude and behavior of people. And as return on advertisements is high pharmaceutical companies are having increased spending in medical drug advertising. ${ }^{2}$ DTCA is now the most prominent type of health communication that the public encounters across the globe. ${ }^{3}$ Historically, for DTCA, advertisers have used the traditional mass media - radio, television, newspapers, magazines, billboards and now these are rapidly being replaced by more popular and emerging forms - of electronic DTCA, which include advertisements on Internet websites, search engine 
marketing, social networking sites, mobile phone and also prescription drug coupons. ${ }^{2-5}$ Internet and social media have taken DTCA across the globe potentially inducing unnecessary demand for medical treatment or promoting therapies with questionable risk and safety profiles. ${ }^{6}$

Currently, the United States and New Zealand are the only countries that allow DTCA of prescription drugs. Most other countries including the European Union and UK do not allow this form of marketing. ${ }^{3}$ The Europe and the UK does not allow even limited forms of DTCA. ${ }^{6}$ Countries such as India, Canada, and South Korea have prohibited DTCA, but they do allow DTC of some formulations or certain advertisements in specified format. ${ }^{2,37}$ In India, DTCA of prescription allopathic drugs (Schedule $\mathrm{H}$ and Schedule X) is not allowed. DTCA of only Ayush formulations that is Ayurvedic, Unani, Siddha and Homeopathy are allowed for public advertising to consumers as long as they do not infringe the Drugs and Magic Remedies Act, 1954. The Drug and Magic Remedies (Objectionable Advertisement) Act and Rules 1954 mentions a list of ailments for which no advertising is permitted. It also prohibits false or misleading advertisements that end up making wrong claims. ${ }^{8}$ Thus, there is a growing need to clearly define the accuracy and educational content of the advertisements and have legislation on consequences for defaulting companies and products with false claims or going awry from the Drug and Magic Remedies (Objectionable Advertisement) Act and Rules 1954. The World Health Organization has also expressed concern on the appropriateness of DTCA and its impact on global health and made a unanimous recommendation to prohibit DTCA at the $30^{\text {th }}$ Annual meeting of countries in $2007 .^{7}$

The debate on the benefits and negative impact of DTCA has been going on around the globe and India too has not been left behind in the debate of legalizing and/or easing the legislation or imposing a total ban on DTCA and studying the increasing impact these advertisements are having. DTCA of drugs is having a profound effect on patients, doctors and health care organizations. It is important to understand the impact it has on the patient behavior. ${ }^{7}$ Pharmaceutical advertising can influence drug consuming behavior and many physicians have negative views of these advertisements. ${ }^{9}$

Against this background, it always will be an interesting proposition to understand the impact of pharmaceutical advertisement on patients' drug consuming behavior. To the best of our knowledge, there are no such studies till date done in India. Hence, this study was undertaken to evaluate whether pharmaceutical advertisements influence the drug consuming behavior of patients. This study was undertaken with an objective to analyze if pharmaceutical advertisements have any influence on population's perception of marketed drugs and to assess of the impact of pharmaceutical advertisements on drug consuming behavior of patients.

\section{METHODOLOGY}

The study was carried out in 300 respondents for a period of 6 months from September to February 2011, at a tertiary care rural hospital in India. The respondents were prebriefed about the study and written informed consent was obtained. Voluntary participation and strict confidentiality were maintained. They were made to take a cross-sectional questionnaire based survey that had 14 close-ended questions validated and approved by internal ethics committee. The questionnaire was prepared in three languages viz., Hindi, Marathi, and English. Responses to the questionnaire were evaluated and analyzed statistically. The study was powered to detect with $80 \%$ probability and alpha $=0.05$. Statistical analysis was performed by using SPSS Version 17 Produced by SPSS Inc., acquired by IBM in 2009. Mann-Whitney test was performed to test the difference of the percentage distributions in age, gender and education, socioeconomic characteristics and drug consumption behavior. A two-tailed $P<0.05$ was considered as statistically significant.

\section{RESULTS}

Of the 300 respondents, 225 (75\%) handed over completed questionnaires. The demographic characteristics of the respondents are represented in Table 1 . The characteristics of the people in terms of their age group, gender and educational qualifications were noted. While more males participated in the study $(n=143)$, around 204 respondents

Table 1: Demographic characteristics of the respondents

\begin{tabular}{|c|c|c|c|c|c|}
\hline \multirow[t]{2}{*}{$\begin{array}{l}\text { Demographic } \\
\text { characteristics }\end{array}$} & \multirow{2}{*}{$\begin{array}{c}\text { Total } \\
\text { number } \\
n=225\end{array}$} & \multicolumn{3}{|c|}{$\begin{array}{l}\text { DTCA influence } \\
\text { (in \%) }\end{array}$} & \multirow[t]{2}{*}{$P$ value } \\
\hline & & Neutral & High & Low & \\
\hline Age in years & & & & & $<0.001$ \\
\hline $18-24$ & 19 & 26 & 42 & 32 & \\
\hline $25-44$ & 73 & 29 & 69 & 02 & \\
\hline $45-64$ & 60 & 15 & 83 & 02 & \\
\hline$>65$ & 71 & 21 & 78 & 01 & \\
\hline Gender & & & & & 0.762 \\
\hline Male & 143 & 23 & 73 & 04 & \\
\hline Female & 65 & 24 & 74 & 02 & \\
\hline Educational status & & & & & 0.011 \\
\hline Less than high school & 16 & 31 & 63 & 6 & \\
\hline Completed high school & 82 & 10 & 81 & 9 & \\
\hline Completed college & 86 & 34 & 64 & 2 & \\
\hline Advanced degree & 39 & 17 & 80 & 3 & \\
\hline
\end{tabular}

*Mann-Whitney test was used for statistical analysis, DTCA: Direct-to-consumer advertising 
were at least 25 years of age and above. Another noticeable fact was that the majority of respondents $(n=207)$ had at least completed high school or had higher education. With respect to DTCA influence in this subset, it was seen that DTCA influence was equal in males and females $(P=0.762)$, educational status had less impact $(P=0.011)$, but the influence was high across all age groups $(P<0.001)$.

Table 2 describes the socioeconomic characteristics with respect to the annual income status, employment and health. Majority of the participating population $(n=169)$ had an annual income $<$ INR 10,000/annum. Only 15 respondents were unemployed and 58 participants were students. Around 200 respondents had a good health status. With respect to DTCA influence in this subset, it was seen that DTCA influence was high $(P<0.001)$ across annual income as well as employment status, whereas the DTCA influence was neutral irrespective of the health status of the respondents.

Table 3 describes the characteristics of the respondents with respect to their drug consuming behavior (No. of

Table 2: Socioeconomic characteristics of the respondents

\begin{tabular}{lccccc}
\hline $\begin{array}{l}\text { Socioeconomic } \\
\text { characteristics }\end{array}$ & $\begin{array}{c}\text { Total } \\
\text { number } \\
\text { n=225 }\end{array}$ & \multicolumn{2}{c}{$\begin{array}{c}\text { DTCA influence } \\
\text { (in \%) }\end{array}$} & P value* \\
\cline { 3 - 5 } & Neutral & High & Low & \\
\hline $\begin{array}{l}\text { Annual income } \\
\text { status (INR) }\end{array}$ & & & & & $<0.001$ \\
$\leq 10,000$ & 169 & 21 & 77 & 02 & \\
$10,000-1,00,000$ & 33 & 21 & 61 & 18 & \\
$1,00,000-10,00,000$ & 11 & 27 & 73 & 0 & \\
$>10,00,000$ & 02 & 100 & 00 & 0 & \\
Employment status & & & & & $<0.001$ \\
\hline Unemployed & 15 & 33 & 27 & 40 & \\
Employed part time & 30 & 10 & 87 & 03 & \\
Employed full time & 101 & 26 & 73 & 01 & \\
Self employed & 16 & 12 & 82 & 06 & \\
\hline Other (students) & 58 & 24 & 74 & 02 & \\
Health status & & & & & $<0.001$ \\
\hline Good & 200 & 74 & 24 & 02 & \\
\hline Poor & 23 & 53 & 17 & 30 & \\
\hline
\end{tabular}

${ }^{*}$ Mann-Whitney test was used for statistical analysis, DTCA: Direct-to-consumer advertising, INR: Indian rupee

Table 3: Characteristics of the respondents' on their drug consuming behavior (number of medicines self-prescribed)

\begin{tabular}{|c|c|c|c|c|c|}
\hline \multirow[t]{2}{*}{$\begin{array}{l}\text { Characteristics of } \\
\text { respondents }\end{array}$} & \multirow{2}{*}{$\begin{array}{c}\text { Total } \\
\text { number } \\
n=225\end{array}$} & \multicolumn{3}{|c|}{$\begin{array}{l}\text { DTCA influence } \\
\text { (in \%) }\end{array}$} & \multirow[t]{2}{*}{$P$ value* } \\
\hline & & Neutral & High & Low & \\
\hline $\begin{array}{l}\text { Drug consuming behavior } \\
\text { (no. of medicines } \\
\text { self-prescribed) }\end{array}$ & & & & & $<0.001$ \\
\hline 0 & 23 & 22 & 44 & 35 & \\
\hline 1 & 42 & 14 & 86 & 00 & \\
\hline 2 & 63 & 22 & 75 & 03 & \\
\hline$>2$ & 73 & 21 & 78 & 01 & \\
\hline
\end{tabular}

medications consumed without the doctor's prescription). It was seen that DTCA influence was high $(P<0.001)$ with respect to self-medication.

Figure 1 depicts DTCA recollected by respondents (Some specified one or more option). It was seen that advertisements featuring antacids, health tonics and supplements, analgesic tablets and creams, antiflatulents and digestives, cold rubs, and tablets as well as cough syrups had a high recall value ( $>50 \%)$.

The opinion of patients on DTCA is captured in Figure 2. It was seen that patients were keen on buying the drugs after an exposure to DTCA. Their other opinions on DTCA were that the drugs marketed were completely safe, unique, highly effective and this form of the advertisement was a positive trend in health care.

When asked for their opinion on what they thought were the negative effects of the DTCAs, a majority $(70 \%)$ felt that the DTCA never mentioned the either the cost or side effects of the marketed product. The other issue which concerned a total of $26.4 \%$ of respondents was the lack of information of the disease and other treatment options. A few respondents also seemed to be concerned that the cost of the drug would increase if they were advertised (Figure 3).

\section{DISCUSSION}

The results of this study demonstrated the trend and perceptions of the DTCA on consumer behavior, which is important not only for patients and physicians but also for regulatory and pharmaceutical organizations. This study shows that the influence of advertising is greater in employed cohort as well as respondents of low socioeconomic status. Further DTCA influence was high across age groups. Educational status was no bar for the DTCA influence. The results from this study signal that DTCA if used properly could serve as an important patient education tool for multiple purposes. It could be used to raise awareness of new disease conditions lead to greater detection and diagnosis of ailments and make patients better aware of treatment options.

The results of this study attempts to highlight the moral obligation on the part of the pharmaceutical industry to increase the health messages in advertisements, and make them more as infomercials instead of commercials, and also to stress less on the specific medical condition and more on the overall disease state.

The benefits and drawbacks of DTCA, the possible remedies, from reforming the nature of advertising to

Journal of Young Pharmacists Vol 6 • Issue 2 • Apr-Jun 2014 


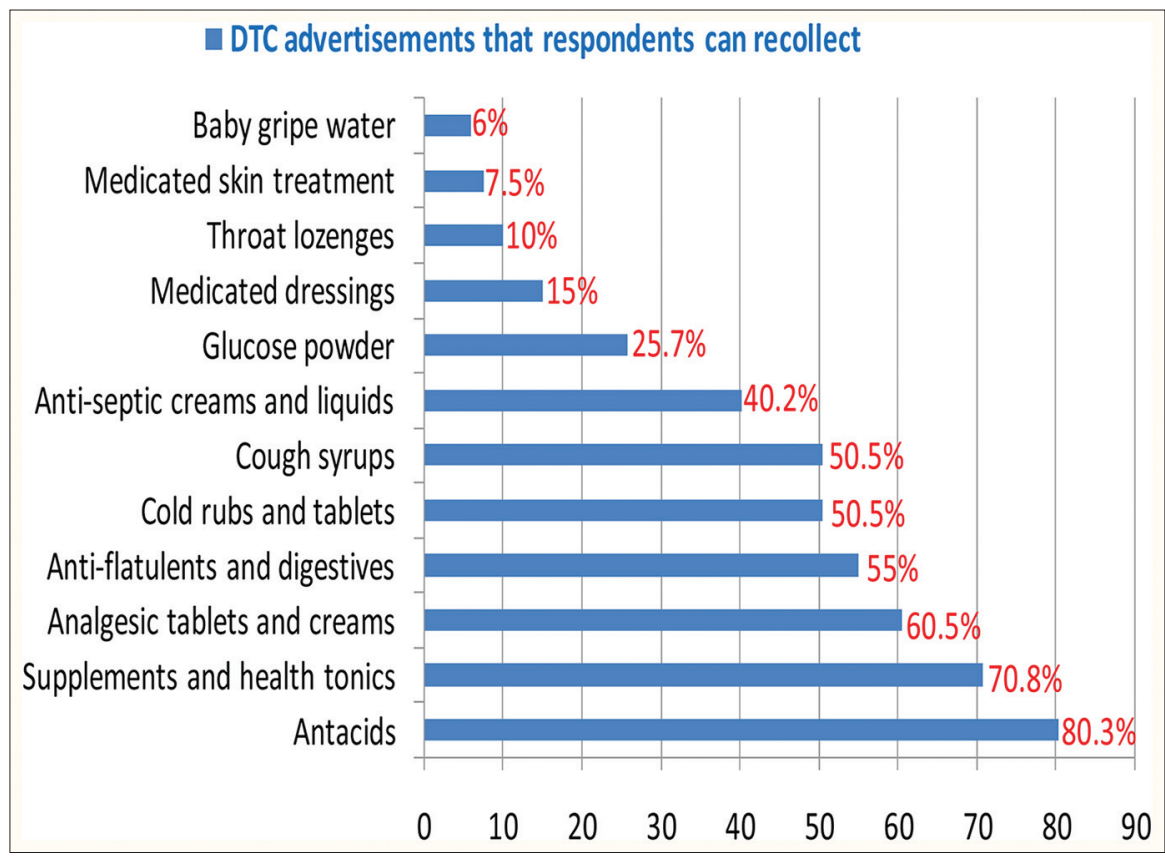

Figure 1: Direct-to-consumer advertising that respondents can recollect

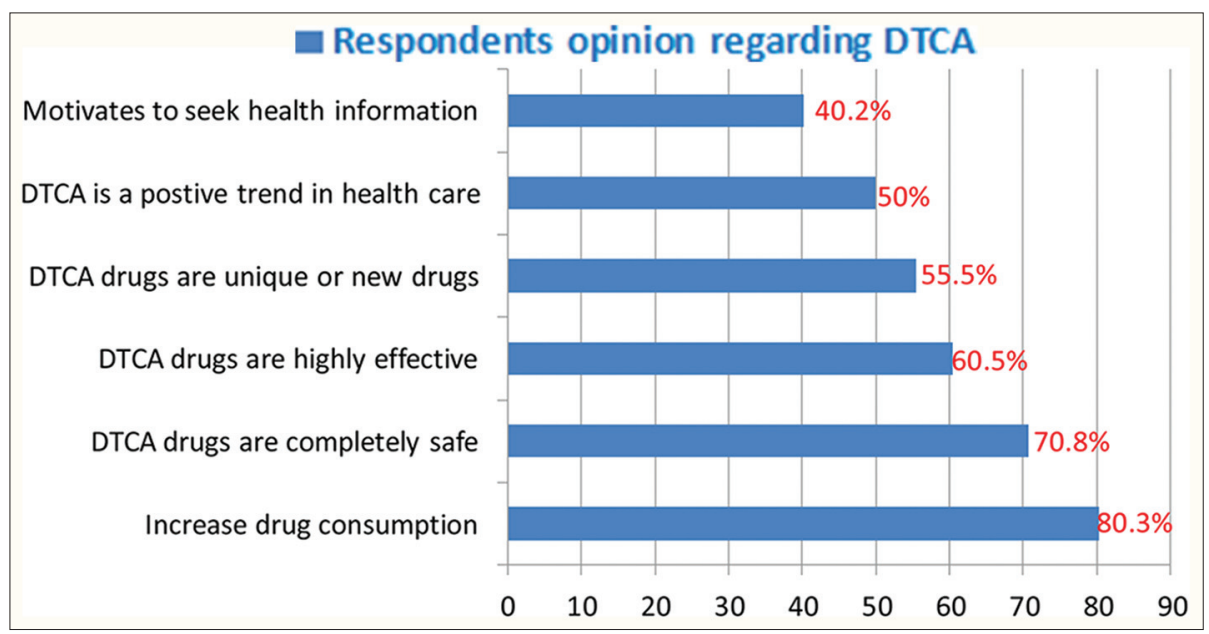

Figure 2: Respondents opinion regarding direct-to-consumer advertising

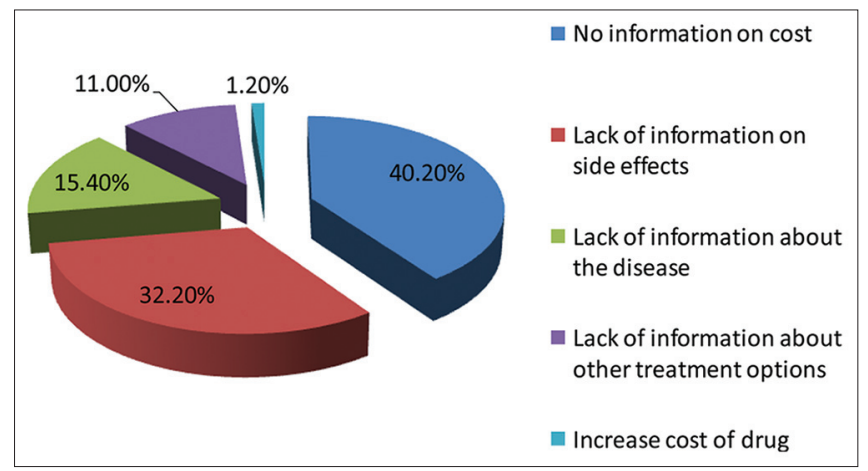

Figure 3: Respondents dissatisfaction with direct-to-consumer advertising

completely banning DTCA have been documented in a few studies. ${ }^{10-13}$ In a paper suggesting possible benefits of DTCA, Parnes et al. ${ }^{14}$ showed that the potential benefit of DTCA is that patient requests may provide the impetus for increased discussion and education about chronic conditions wherein patients may be required to take multiple drugs and consumption may be for longer duration.

In their paper, Murray et al., ${ }^{10}$ have mentioned that DTCA has positive and negative effects on health behaviors, health service utilization and the doctor-patient relationship with a greatest impact on people of low socioeconomic status. Donohue et al. ${ }^{11}$ in their study showed that spending on DTCA has continued to increase in recent years in spite of the criticisms leveled against it. 
Mintzes et al., ${ }^{12}$ in their published study showed that DTCA may increase sales but appropriateness of medication may suffer. Interestingly, Wilkes et al., ${ }^{4}$ showed survey respondents response to a hypothetical denied the request for prescription of DTCA drugs.

In another study by Frosch et al. ${ }^{9}$ expressed that to minimize potential harm and maximize the benefits of DTCA for population health, steps should be taken for improving the quality and quantity of information to enable consumers to better self-identify whether treatment is indicated, enable consumers to more realistically appraise the benefits, and also to enable consumers to better attend to the risks associated with prescription drugs.

Ventola $^{3}$ in his paper apart from writing about the arguments in support of DTCA has also raised five valid concerns on DTCA viz. (a) Manufacturers often use DTCPA to promote expensive or "copycat" drugs that might not offer any significant benefits over older and cheaper medications; (b) manufactures encourage drug over utilization; (c) leads to inappropriate prescribing; (d) over emphasizing on the benefits of the drugs; and (e) promotes new drugs before safety profiles are fully known. These points are very relevant in Indian context.

Frosch et al. ${ }^{9}$ has proposed possible guidelines and described that DTCA does have benefits, although on the same hand there are significant risks. And efforts should be made to reduce the potential harm and maximize the benefits of DTCA for population health. The authors suggest that the quality and quantity of information should be upgraded to aid the consumers to self-identify whether treatment is indicated, more realistically assess the risks - and benefits associated with prescription drugs.

One goal of DTCA is to educate and provide physicians and patients with information about marketed drugs, but this can result in an increase in drug expenditures, misleading claims, wrong usage of branded drugs that at times can compromise safety of the patients. ${ }^{6}$ DTCA represents a global challenge with concerns regarding how to appropriately regulate dissemination of information on television, internet, and sponsored links on search engines and social media, which do not have geopolitical boundaries. ${ }^{6}$ Also these are growing concerns pointed out by critics that DTCA are not effective in presenting the drug risks and benefit. This issue assumes more significance in today's times when complex drugs such as biologics and biosimilars are invading the market place. ${ }^{6}$

In India, DTC marketing and promotions are done to create health, hygiene and disease awareness as well as for propagating family planning programs. ${ }^{2}$ India also permits the DTC of AYUSH drugs and even AYUSH formulations could be with potential side effects and dangerous for people already suffering from a disease or on medication. Although DTC of allopathic drugs is banned, as India is rapidly technologically advancing and Indians getting exposed to the internet, Indian population is being increasingly exposed to advertising for prescription drugs despite legal prohibitions. ${ }^{13}$

A patient physician communication on the disease and the drug is always considered fundamental when it comes to disease management. ${ }^{15}$ Besides this, the need of the hour, for India is to increase vigilance with respect to any inappropriate use of DTCA on all powerful mediums of radio, television and internet. ${ }^{2}$ In India there is an immediate need to closely monitor the claims, cost, risks and particularly the quality of independent and unbiased information regarding AYUSH or prescription drugs on DTCA including on the internet. Pharmacovigilance centers which have been established under National Pharmacovigilance Program could help in playing an essential role in this regard.

Hence, pharmaceutical companies and regulatory organizations, have a burden of responsibility-both moral and ethical, to regulate the content marketed on internet, social media and shown on television, to prevent gullible people from falling prey to faulty medication and on the same hand provide correct information, with specific disease, side-effects, educating the masses and helping them reap benefits of early detection and prior information.

Educative infomercials would be a step ahead from the pure marketing commercials. Furthermore, in order to provide this information, compromising in regulatory guidelines or bowing to pure monetary interests and economic pressure is definitely not advisable. DTCA must have increasing health messages with more emphasis on overall disease state and less emphasis on the specific medication. In a country like India, where patient trusts the words of the health care provider, properly regulated, DTCA can also lead to greater detection and diagnosis of ailments. There exists a moral obligation on the part of the pharmaceutical industry to make patients better aware of treatment options.

\section{CONCLUSION}

Our study shows that DTCA has a positive influence on the increase in the drug consuming behavior of patients. Since our study shows that DTCA motivates to seek health 
information; it can serve as an important patient education tool to raise awareness of new disease conditions.

\section{ACKNOWLEDGMENTS}

Special thanks to Mr. Disheet Shah, Research Fellow, University of Nottingham, United Kingdom toward his significant and valuable contribution toward this article in terms of help with the data management.

\section{REFERENCES}

1. Bell RA, Kravitz RL, Wilkes MS. Direct-to-consumer prescription drug advertising and the public. J Gen Intern Med 1999;14:651-7.

2. Khosla P, Khosla A. Direct to consumer advertising of prescription drugs on internet: A Boon or a Curse. Indian J Pharmacol 2011;43:483-4.

3. Ventola CL. Direct-to-consumer pharmaceutical advertising: Therapeutic or toxic? P T 2011;36:669-84.

4. Liang BA, Mackey TK. Stem cells, Dot-com. Sci Transl Med 2012; 4(151): $1-4$.

5. Mackey TK, Yagi N, Liang BA. Prescription drug coupons: Evolution and need for regulation in direct-to-consumer advertising. Res Social Adm Pharm 2014;10:588-94.

6. Liang BA, Mackey TK. Stem cells, Dot-com. Sci Transl Med 2012;4:1-4.
7. Wilkes MS, Bell RA, Kravitz RL. Direct-to-consumer prescription drug advertising: Trends, impact, and implications. Health Aff (Millwood) 2000;19:110-28.

8. The Drugs and Magic Remedies (Objectionable Advertisements) Act, 1954. Available from: http://www.rfhha.org/images/pdf/Hospital_Laws/ Drugs_magic_remedies_(\%20advertisement)_act.pdf. [Last accessed on 2014 Jan 26].

9. Frosch DL, Grande D, Tarn DM, Kravitz RL. A decade of controversy: Balancing policy with evidence in the regulation of prescription drug advertising. Am J Public Health 2010;100:24-32.

10. Murray E, Lo B, Pollack L, Donelan K, Lee K. Direct-to-consumer advertising: Public perceptions of its effects on health behaviors, health care, and the doctor-patient relationship. J Am Board Fam Pract 2004;17:6-18.

11. Donohue JM, Cevasco M, Rosenthal MB. A decade of direct-to-consumer advertising of prescription drugs. N Engl J Med 2007;357:673-81.

12. Mintzes B, Barer ML, Kravitz RL, Kazanjian A, Bassett K, Lexchin J, et al. Influence of direct to consumer pharmaceutical advertising and patients' requests on prescribing decisions: Two site cross sectional survey. BMJ 2002;324:278-9.

13. Lal A. Pharmaceutical drug promotion: How it is being practiced in India? J Assoc Physicians India 2001;49:266-73.

14. Parnes B, Smith PC, Gilroy C, Quintela J, Emsermann CB, Dickinson LM, et al. Lack of impact of direct-to-consumer advertising on the physician-patient encounter in primary care: A SNOCAP report. Ann Fam Med 2009;7:41-6.

15. Hassali M, Shafie A, Khan T. General public expectation from the communication process with their healthcare providers. J Young Pharm 2012;4:193-8. 